
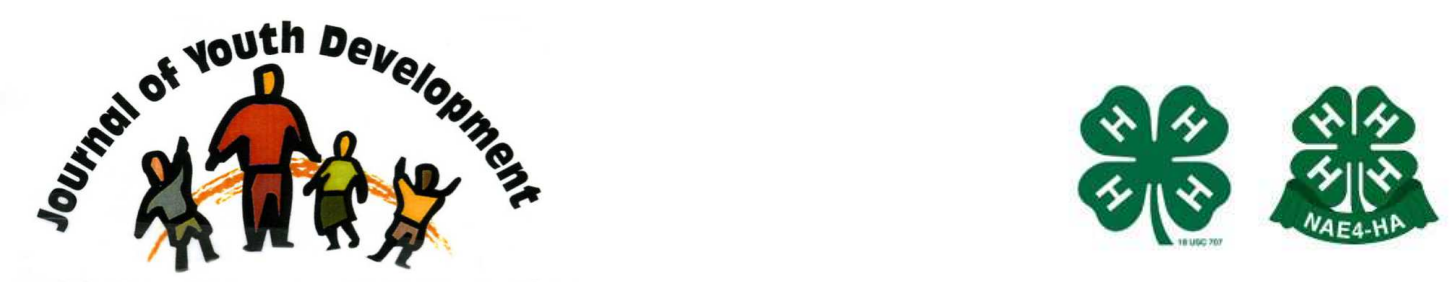

Bridging Research \& Practice

\title{
Intergenerational Service Learning Program Improves Aging Knowledge and Expectations and Reduces Ageism in Younger Adults
}

\author{
Sarah L. Francis \\ Food Science and Human Nutrition \\ Iowa State University \\ Ames, IA \\ slfranci@iastate.edu \\ Jennifer A. Margrett \\ Human Development and Family Studies \\ Iowa State University \\ Ames, IA \\ Margrett@iastate.edu \\ Kara Hoerr \\ Food Science and Human Nutrition \\ Iowa State University \\ Ames, IA \\ Kara.hoerr@iastate.edu \\ Marc J. Peterson \\ 4-H and Youth Development \\ Iowa State University \\ Ames, IA \\ marc@iastate.edu \\ Abbie Scott \\ Food Science and Human Nutrition \\ Iowa State University \\ Ames, IA \\ Abbie2890@iastate.edu \\ Warren D. Franke \\ Department of Kinesiology \\ Iowa State University \\ Ames, IA \\ wfranke@iastate.edu
}




\title{
JOURNAL OF YOUTH DEVELOPMENT \\ bridging research and practice

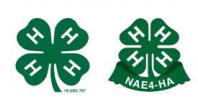

Volume 9, Number 3, Fall 2014

Article 140903PA001

\section{Intergenerational Service Learning Program Improves Aging Knowledge and Expectations and Reduces Ageism in Younger Adults}

\author{
Sarah L. Francis, Jennifer A. Margrett, Kara Hoerr, Marc J. Peterson, Abbie Scott and \\ Warren D. Franke \\ Iowa State University
}

\begin{abstract}
This article discusses a study which evaluated the effects of an intergenerational service-learning exergaming program for older adults on younger adults' aging knowledge, expectations, and perceptions. Eighteen college students (ages 19-26 years) served as trainers for an 8-week exergaming physical activity program for older adults (12 contact hours). Questionnaires assessing aging knowledge, ageist attitudes and aging expectations were completed at Weeks 1, 8, and 25 (follow-up); program evaluations were completed at Weeks 8 and 25. Significant improvement from Week 1 to Week 25 was found for: Aging knowledge scores $(p<0.03)$, positive aging expectations regarding mental health $(p<.02)$, positive aging expectations regarding cognitive health $(p=.043)$, overall aging expectations $(p<.05)$, ageism (stereotypes) $(p<.02)$ and ageism (separation) $(p=.000)$. All trainers ranked their experience as "good to excellent." This intergenerational service learning program is effective in improving aging knowledge, expectations and perceptions.
\end{abstract}

\section{Introduction}

"Ageism" is a multi-faceted problem that perpetuates negative stereotypes toward older adults through actions, attitudes and beliefs (Butler, 1969; Palmore, 1999). Ageism can stem from a lack of knowledge about aging, limited contact with older adults, and fear of aging, leading to distancing oneself from older adults (Ory, Hoffman, Hawkins, Sanner, \& Mockenhaupt, 2003). The awareness of ageism alone, without education or programming, does not affect reductions in this form of discrimination (Schwalb, \& Sedlacek, 1990). Providing opportunities for younger adults to engage in meaningful intergenerational interactions which allow them to learn about aging and develop positive attitudes toward the aging process can contribute significantly to reducing ageism. One means of doing this is through intergenerational service-learning programs. 
Service learning programs provide younger adults with the opportunity to apply what they have learned in an "academic setting" to a "real world setting." Service learning differs from traditional community-based volunteering opportunities in that it is intended to foster younger adult learning while meeting the service needs of a community via blending learning and handson experience (Karasik, \& Wallingford, 2007; Long, Larsen, Hussey, \& Travis, 2001).

Intergenerational programs allow both generations to build personal relationships and learn new skills through interactions with each other (Kaplan, Liu, \& Radhakrishna, 2003). Younger adults, when given the chance to interact with older adults, have a sense of purpose in what they are doing, feel more like they belong, and perform better in school than peers who have limited to no interaction with older adults (Butts, \& Chana, 2007). Thus intergenerational programs can be an effective strategy to sensitize younger adults to their attitudes regarding aging and to promote better understanding about the aging process.

The purpose of this pilot study was to evaluate the effects of the Living (well through) Intergenerational Fitness and Exercise (LIFE) Program, an intergenerational service-learning exergaming-based physical activity program for older adults, on younger adults' aging knowledge and expectations, and ageist viewpoints.

\section{Methods}

Program Design. The LIFE Program, a service learning intergenerational program designed to be delivered through Extension, uses a reverse intergenerational approach wherein the younger adults (trainers) took on the role of "mentor" rather than a "mentee."

The theoretical base for the LIFE Program is the Whole Person Wellness Model which is comprised of six wellness dimensions encompassing holistic health including physical, emotional, spiritual, intellectual, vocational, and social wellness (Montague, Piazza, Peters, Eippert, \& Poggiali, 2002). The wellness dimensions applicable to the LIFE Program trainers were:

- Social wellness, stresses the development and maintenance of healthy relationships;

- Intellectual wellness, encourages the use of one's mind to form a better appreciation and understanding of oneself and others;

- Emotional wellness, encompasses awareness and recognition of one's feelings and reveals the degree to which individuals feel optimistic and excited about themselves and life;

- Vocational wellness, highlights the process of defining and attaining personal and professional interest through meaningful activities (Montague, et al., 2002).

Prior to serving as a LIFE Program trainer, all trainers participated in an eight-hour workshop where they were taught myths and facts about aging, learned how to facilitate interactive games, received safety training for older adult physical activity and first aid training, and took part in a $\mathrm{Wii}^{\circledR}$ practicum.

The LIFE Program took place over a 24-week period at five congregate meal sites and two lowincome senior apartment buildings in rural towns in central Iowa (Table 1). Trainers facilitated the eight week onsite exergaming program where they had approximately 12 hours of contact time ( 1.5 hours/week $\times 8$ weeks) with older adults (participants). During this time, trainers established a relationship with participants by their personal interactions during the exergaming sessions and learning more about the participants during the interactive games. 


\section{Table 1}

LIFE Program Description

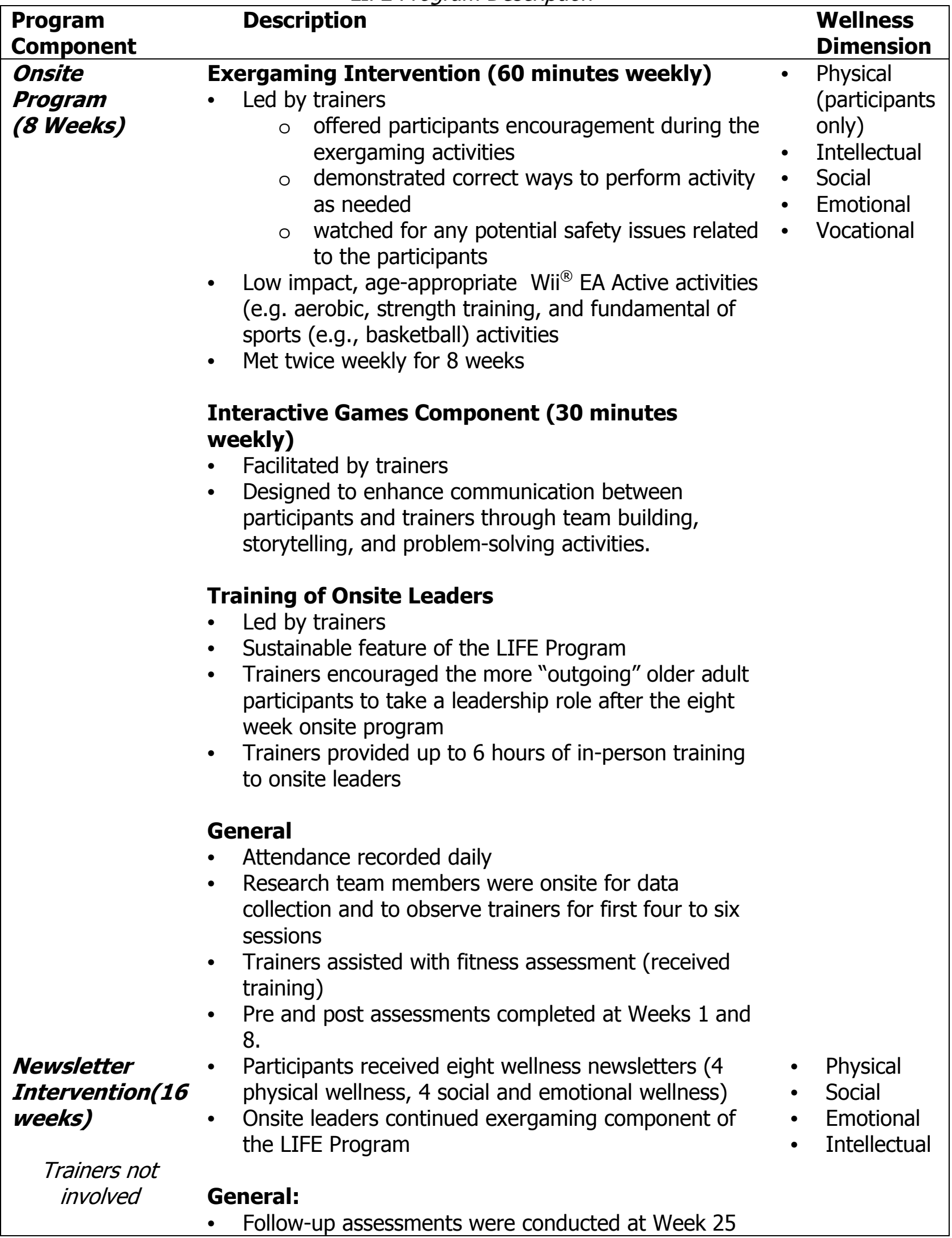


Recruitment. High school and college students were recruited using convenience sampling methods including e-mails sent to university student list-serves, word of mouth, flyers, and inperson presentations (e.g. 4-H meetings, youth groups). Eighteen students (ages 19-26 years) volunteered to serve as trainers with the majority being undergraduate females who had occasional contact with older adults. Participants were community-residing older adults (age $60+$ ); these data have been reported elsewhere (Strand, Francis, Margrett, Franke, \& Petersen, in press). Each LIFE Program site had 3-17 participants with 2-3 trainers. The study protocol was approved by the university's Institutional Review Board. All trainers signed informed consent.

Program Evaluation. Trainers completed a questionnaire during Week 1 (start of the workshop), Week 8 (last day of the onsite program), and Week 25 (sent via mail one week after the program closed), comprised of three valid and reliable survey tools. Aging knowledge (measure of intellectual wellness) was assessed using the Facts on Aging Quiz $(a=0.15)$ which is comprised of 25 multiple-choice aging-related questions (Harris, Changas, \& Palmore, 1996).

Ageism (measure of social and intellectual wellness) was measured with the Fabroni Scale on Ageism (FSA) which uses a Likert-type scale ranging from 1 (strongly disagree) to 4 (strongly agree) (Rupp, Vodanovich, \& Credé, 2005). The 29 questions contained in the FSA $(a=0.86)$ assessed both affective and cognitive aspects of ageism and has three subscales: stereotypes (10 items, $a=0.79$ ), separation ( 8 items, $a=0.76$ ), affective attitudes ( 5 items, $a=0.70$ ) (Rupp, Vodanovich, \& Credé, 2005). Aging separation refers to the tendency to avoid older adults, while affective attitudes refer to discrimination.

Aging expectations (measure of emotional wellness) were determined using the 12-item Expectations Regarding Aging (ERA-12) scale $(a=0.89)$ which measures expectations individuals have about how their health and cognitive function will be when they have become an older adult (Sarkisian, Steers, Hays, \& Mangione, 2005). This tool examines four areas of aging expectations: (1) physical health, (2) mental health, (3) cognitive function, and (4) global expectations. Each score is based on a 100 range scale and was calculated using the ERA-12 scoring instructions (Sarkisian, Steers, Hays, \& Mangione, 2005).

Trainers also completed qualitative evaluations at Weeks 8 and Week 25 regarding their experience (measure of vocational wellness). Most $(n=11)$ also participated in focus group discussions about their LIFE Program experience ( 6 as part of a "trainers only" focus group and 5 as part of a "participants and trainers" focus group). Trainers who participated in the focus group discussions received a wellness journal for their participation.

Data Analysis. Data were analyzed using the Statistical Package for Social Science for Windows (SPSS for Windows, version 18.0, 2010). Demographic information and qualitative data were analyzed using descriptive statistics. Paired sample $t$-tests were used to assess changes in variables over time. Focus group discussions were transcribed by an independent transcriptionist and analyzed for common themes by the researchers per common practice (Krueger \& Casey, 2009).

\section{Results}

All trainers completed the LIFE Program (Table 2). The most frequently reported reasons for serving as a trainer were "interested in older adult wellness," $(n=17)$ and it was a "fun way to volunteer" $(n=16)$. 
Table 2

Trainer Characteristics

\begin{tabular}{|c|c|c|}
\hline CHARACTERISTIC & NUMBER $^{\mathrm{a}}$ & PERCENT \\
\hline \multicolumn{3}{|l|}{ Sex } \\
\hline Male & 1 & 5.6 \\
\hline Female & 17 & 94.4 \\
\hline \multicolumn{3}{|l|}{ Age } \\
\hline$\leq 20$ years & 4 & 22.2 \\
\hline$\overline{21-25}$ years & 13 & 72.2 \\
\hline$\geq 26$ years & 1 & 5.6 \\
\hline \multicolumn{3}{|l|}{ Ethnicity } \\
\hline White & 15 & 83.3 \\
\hline Asian & 3 & 16.7 \\
\hline \multicolumn{3}{|l|}{ Year of School } \\
\hline $1^{\text {st }}$ Year College & 1 & 5.6 \\
\hline $2^{\text {nd }}$ Year College & 1 & 5.6 \\
\hline $3^{\text {rd }}$ Year College & 7 & 38.9 \\
\hline $4^{\text {th }}$ Year College & 7 & 38.9 \\
\hline Graduate Student & 2 & 11.1 \\
\hline \multicolumn{3}{|l|}{ Daily Contact with Older Adults } \\
\hline Never & 4 & 22.2 \\
\hline Occasionally & 11 & 61.1 \\
\hline Several times per day & 3 & 16.7 \\
\hline \multicolumn{3}{|l|}{ Lived with older adult relative in last 5 years } \\
\hline $\begin{array}{lll}2 & \text { Yes }\end{array}$ & 5 & 27.8 \\
\hline No & 13 & 72.2 \\
\hline
\end{tabular}

Note: ${ }^{a}$ Total number of trainers is 18

Improvement was detected in aging knowledge, aging expectations for mental and cognitive function, as well as overall aging expectations (total ERA-12 score) and ageism (stereotype and separation) as shown in Table 3. 
Table 3

Change in Aging Knowledge, Aging Expectations, and Ageism

\begin{tabular}{|c|c|c|c|c|}
\hline Measure (max score) & & $\begin{array}{r}\text { Week 1 } \\
\text { Mean ( }( \pm S D)\end{array}$ & $\begin{array}{r}\text { Week } 8 \\
\text { Mean }( \pm \text { SD) }\end{array}$ & $\begin{array}{r}\text { Week 25 } \\
\text { Mean }( \pm S D)\end{array}$ \\
\hline Aging Knowledge (25) & & $10.78 \pm 2.73$ & $\begin{array}{r}12.33 \pm 1.55 \\
p=.027^{\mathrm{a}}\end{array}$ & $\begin{array}{r}13.39 \pm 2.62 \\
p=.010^{b} \\
p=.001^{c}\end{array}$ \\
\hline \multirow[t]{4}{*}{ Aging Expectations } & Physical Health (100) & $49.07 \pm 22.49$ & $\begin{array}{r}52.78 \pm 21.39 \\
p=.492^{a}\end{array}$ & $\begin{array}{r}55.56 \pm 20.01 \\
p=.489^{b} \\
p=.240^{c}\end{array}$ \\
\hline & Mental Health (100) & $81.48 \pm 12.61$ & $\begin{array}{r}89.35 \pm 10.91 \\
p=.017^{a}\end{array}$ & $\begin{array}{r}91.20 \pm 12.86 \\
p=.481^{b} \\
p=.005^{c}\end{array}$ \\
\hline & Cognitive Function (100) & $50.46 \pm 15.25$ & $\begin{array}{r}58.33 \pm 18.58 \\
p=.043^{b}\end{array}$ & $\begin{array}{r}59.72 \pm 20.39 \\
p=.755^{b} \\
p=.071^{c}\end{array}$ \\
\hline & Total ERA-12 Score (100) & $60.34 \pm 5.17$ & $\begin{array}{r}62.96 \pm 11.86 \\
p=.046^{a}\end{array}$ & $\begin{array}{r}68.83 \pm 14.18 \\
p=.051^{b} \\
p=.021^{c}\end{array}$ \\
\hline \multirow[t]{3}{*}{ Ageism } & Stereotype $(40)^{d}$ & $30.22 \pm 3.88$ & $\begin{array}{r}32.67 \pm 2.4 \\
p=.016^{a}\end{array}$ & $\begin{array}{r}33.47 \pm 2.4 \\
p=.105^{b} \\
p=.000^{c}\end{array}$ \\
\hline & Separation(32) & $26.44 \pm 2.68$ & $\begin{array}{r}25.33 \pm 1.81 \\
p=.096^{a}\end{array}$ & $\begin{array}{r}27.17 \pm 2.77 \\
p=.108^{b} \\
p=.012^{c}\end{array}$ \\
\hline & Affective Attitudes (20) & $10.53 \pm .717$ & $\begin{array}{r}10.12 \pm 1.27 \\
p=.186^{a}\end{array}$ & $\begin{array}{r}10.39 \pm 1.61 \\
p=.641^{b} \\
p=.881^{c}\end{array}$ \\
\hline
\end{tabular}

Note: ${ }^{\mathrm{a}}$ Change from Week 1 to Week $8 ;{ }^{\mathrm{b}}$ Change from Week 8 to Week $25 ;{ }^{\mathrm{C}}$ Change from Week 1 to Week $25 ;{ }^{d}$ Increased stereotype score reflects a decrease in the number of ageist stereotypes believed

Trainers' aging knowledge scores continuously increased Week 1 (10.78) through Week 25 (13.39) with all increases being statistically significant $(p<0.03)$. Expectations about aging and mental health improved significantly between Weeks 1 and $8(p=.017)$ and Weeks 1 and 25 $(p=.005)$. A significant increase in expectations about aging and cognitive function was detected from Week 1 to Week $8(p=.043)$. Total ERA-12 scores significantly increased from Week 1 to Week $8(p=.046)$ and Week $25(p=.021)$.

Significant improvements $(p=.016)$ in ageism stereotype scores were detected (increased score reflects decreased ageism stereotypes) from Week 1 to Weeks $8(p=.016)$ and $25(p=.000)$. The reduction in ageism stereotypes is articulated well by a trainer who commented "I got to understand the older generation a bit more." The ageism separation scores significantly improved from Week 1 to Week $25(p=.000)$. The increased desire to have contact with older 
adults is best illustrated by a trainer who stated "[I enjoyed] being able to get to know the participants and watching their physical and emotional changes. "

All trainers ranked their experience as "good to excellent" at both Weeks 8 and 25 as noted by the statement "I really enjoyed all the participants, and they seemed like they [the participants] enjoyed it as well." Approximately $72 \%$ (13 out of 18) of trainers reported positive changes in how they perceive older adults with one reporting "I underestimated their social and physical capabilities." Some were surprised at how enjoyable and social older adults can be with younger adults, as indicated by statements such as "They [participants] really do enjoy the younger generation trying to help them" and "There is so much to learn from them."

At Week 8 , a majority ( $n=12$ out of $18,67 \%$ ) reported that the most enjoyable aspect of the LIFE Program was getting to know the participants, interacting with them weekly, and seeing the participants' physical improvements. One trainer commented, "It was interesting to see them [participants] improve themselves and they [participants] often told us they could do more and they had more energy to do things or be more motivated."

Sixteen weeks following the onsite program, nearly all trainers $(n=15)$ still reported that interacting with the participants was their favorite program attribute. All conveyed they felt they got to know the older adults by participating in the LIFE Program. Most ( $n=14$ out of 18 , $78 \%$ ) reported viewing older adults in a more positive light as a result of the LIFE Program at Week 8; this decreased slightly at Week 25 ( $n=13$ out of $18,72 \%)$. The remaining 4 and 5 trainers reported no change, respectively.

\section{Discussion}

These results suggest the LIFE Program was effective in improving aging knowledge and aging expectations among younger adults; however, the generalizability of these results is limited due to the small sample size and predominately female group of trainers. The LIFE Program was also effective at lowering the number of ageist stereotypes and the tendency for younger adults to remain separate from older adults. These changes were maintained and/or continued to improve up to four months after the initial intergenerational interaction. Thus, our findings suggest that weekly, meaningful interaction between older and younger adults of as little as 12 hours of contact time over an 8-week period can result in sustained improvements in younger adults' aging knowledge, expectations and perceptions.

In designing the service learning component of the LIFE Program, many of the programming attributes recommended by Karasik and Wallingford (2007) were included:

1. Locations were within a reasonable travel time from campus (maximum time was 20 minutes one-way) and were safe and easily accessible,

2. The selected activities (e.g. interactive games) were beneficial to both participants and trainers,

3. Trainers received comprehensive training that clearly stated the LIFE Program goals and objectives, and

4. Protocols were put in place to limit trainer confusion and frustration

Additionally, the regular interaction each trainer had with participants likely contributed to the changes detected. Dauenhauer, Steitz, Aponte, and Faria (2010) reported that students who had frequent contact with older adults showed greater improvement in select gerocompetencies than those with less contact time. By including these recommended programming attributes 
and the regular intergenerational contact, the likelihood of seeing measurable change due to the LIFE Program was enhanced.

Aging Knowledge. While the improvement noted for aging knowledge was significant, the change detected from Week 1 (43\% correct) to Week 25 (52\% correct) was small at about 9 percent. The modest change detected in our sample is similar to Scott, Minichiello, and Browning (1998) who found that younger adults participating in an older adult education program increased knowledge, as measured by the Facts on Aging Quiz, by about two percent after a nine hour intervention that spanned over a three week time frame. The larger, albeit modest, knowledge change detected as a result of participating in the LIFE Program may be attributable to the 12 hours of total contact time the trainers had with the participants. Scott and others (1998) found the more time students spent with older adults, the higher their aging knowledge.

Aging Expectations. These results also suggest the LIFE Program is effective in increasing the number of positive aging expectations for cognitive function and mental health, and overall general aging expectations held by college students. The improvement seen at Weeks 8 and 25 suggest that the 12 hours of substantive intergenerational interaction was adequate to improve aging expectations and that these changes were maintained and/or continued to improve even after the weekly interaction ceased.

Promoting more positive aging expectations not only helps encourage better understanding of the aging process and older adults but can also lead to improved health of younger adults, since positive aging expectations can positively affect health and wellness through the lifespan (Roters, Logan, Meisner, \& Baker, 2009). The change in aging expectations for this group may also be explained by the education the trainers received during the training workshop, since being uninformed about aging may contribute to negative aging expectations (Sarkisian, et al., 2005).

Ageism. Frequent exposure to older adults reduces negative feelings or resistance to working with older adults (Allen, et al., 2009). Thus, the regular interaction between the trainers and participants likely contributed to the change detected in ageism (i.e., stereotype and separation).

The additional eight hours of training trainers received prior to implementing the LIFE Program may also have contributed to the reduction in ageism. Education about aging myths and realities has been suggested as one means of reducing ageism (Ory, et al., 2003).

Furthermore, the reduction in ageism (stereotypes) could also be due, in part, to the gender of most of the trainers. In other intergenerational programs, gender has been shown to influence attitudes toward aging, with females, ages 17 to 18 years holding less negative aging attitudes than males of the same age (Scott, Minichiello, \& Browning, 1998; Yilmaz, Kisa, \& Zyenelo, 2012). Similarly, in a study conducted by Kalavar (2010) ageism scores showed male college students displaying more negative attitudes than female college students.

Finally, the reduction detected in ageism for stereotypes may have been influenced by the LIFE Program's emphasis on physical activity. Ory and colleagues (2003) noted that one way to combat aging stereotypes was to provide networks for intergenerational interactions, in particular, recreational and fitness activities, which is what the LIFE Program did. 


\section{Conclusions}

This pilot study demonstrated that the LIFE Program can be a successful strategy in increasing younger adults' aging knowledge and improving aging expectations while reducing ageist views. By implementing an intergenerational service learning program like the LIFE Program (program website address to be placed here after blinded review) through community organizations like Extension, the occurrence of ageism may decrease in younger adults, leading to more supportive and positive age-supporting behaviors toward themselves and others.

\section{Key Messages for Youth Development Professionals}

Based on the findings from the LIFE Program pilot study, when designing and implementing an intergenerational service-learning program that leads to increased aging knowledge, improved aging expectations, and reduced ageism in younger adults it is important to:

- Provide comprehensive training prior to the intergenerational program for the younger adults that discusses myths and realities about aging.

- Develop structured activities that promote meaningful intergenerational interaction and dialog.

- Allow for adequate intergenerational interaction time and program duration in order to facilitate positive relationship building between both younger and older adults.

Acknowledgments: We thank the younger adult trainers who led the onsite program component, the older adults who participated, and the congregate meal sites and senior apartments that hosted the LIFE Program. Funding was provided by the Rural Health and Safety Education Competitive Program of the USDA National Institute of Food and Agriculture, grant number 2010-03643.

\section{References}

Allen, P.D., Cherry, K.E., \& Palmore, E. (2009). Self-reported ageism in social work practitioners and students. Journal of Gerontological Social Work, 52:124-134.

Butler, R.N. (1969). Age-ism: Another form of bigotry. Gerontologist, 9 (4): 243-246.

Butts, D.M., \& Chana, K. (2007). Intergenerational programs promote active aging. The Journal on Active Aging, July/Aug: 34-39.

Dauenhauer, J.A., Steitz, D.W., Aponte, C.I., \& Faria, D.F. (2010). Enhancing student gerocompetencies: evaluation of an intergenerational service learning course. Journal of Gerontological Social Work, 53(4), 319-335.

Harris, D.K., Changas, P.S., \& Palmore, E.B. (1996). Palmore's first Facts on Aging Quiz in a multiple-choice format. Educational Gerontology, 22(6): 575-589.

Kalavar, J. (2010). Examining Ageism: Do male and female college students differ? Educational Gerontology, 27(6): 507-513.

Kaplan, M., Liu, S., \& Radhakrishna, R. (2003). Intergenerational programming in Extension: 
needs assessment as a planning tool. Journal of Extension, 41(4): 4FEAS. Retrieved from: http://www.joe.org/joe/2003august/a5.php.

Karasik, R.J., \& Wallingford, M.S. (2007). Finding community: Developing and maintaining effective intergenerational service-learning partnerships. Educational Gerontology, 33: 775-793.

Krueger, R.A., \& Casey, M.A. (2009). Focus groups: A practical guide for applied research. Los Angeles: SAGE.

Long, A.B., Larsen, P., Hussey, L., \& Travis, S.S. (2001). Organizing, managing, and evaluating service learning projects. Educational Gerontology, 27:3-21.

Montague, J., Piazza, W., Peters, K., Eippert, G., \& Poggiali, T. (2002) The wellness solution. The Journal on Active Aging, 17-20. Retrieved on March 1, 2013 from http://www.aahf.info/sec news/section/pdf/thewellnesssolution2.pdf.

Ory, M., Hoffman, M.K., Hawkins, M., Sanner, B., \& Mockenhaupt, R. (2003). Challenging aging stereotypes strategies for creating a more active society. American Journal of Preventive Medicine, 25(3Sii): 164-171.

Palmore, E.B. (1999). Ageism: Negative and positive. New York: Springer.

Roters, J., Logan, A.J., Meisner, B.A., \& Baker, J. (2009). A preliminary study of perceptions of aging in athletes and non-athletes. Psychology of Sport and Exercise, 11: 67-70.

Rupp, D.E., Vodanovich, S.J., \& Credé, M. (2005). The multidimensional nature of ageism: Construct validity and group differences. The Journal of Social Psychology, 145(3), 335-362.

Sarkisian, C.A., Steers, W.N., Hays, R.D., \& Mangione, C.M. (2005). Development of the 12-item Expectations Regarding Aging Survey. The Gerontologist, 45(2): 240-248.

Schwalb, S., \& Sedlacek W. (1990). Have college students' attitudes toward older people changed? Journal of College Student Development. 31:127-132.

Scott, T., Minichiello, V., \& Browning, C. (1998). Secondary school students' knowledge of and attitudes towards older people: Does an education intervention programme make a difference? Ageing and Society, 18: 167-183.

Strand, K.A., Francis, S.L., Margrett, J.A., Franke, W.D., \& Peterson, M.J. (in press). Community-based exergaming and wellness program increases physical activity and subjective health among rural older adults. Journal of Aging and Physical Activity.

Yilmaz, D., Kisa, S., \& Zeyneloğlu, S. (2012). University students' views and practices of ageism. Ageing International, 37:143-154.

(C) Copyright of Journal of Youth Development Bridging Research and Practice. Content may not be copied or emailed to multiple sites or posted to a listserv without copyright holder's express written 
permission. Contact Editor at: patricia.dawson@oregonstate.edu for details. However, users may print, download or email articles for individual use. 